\title{
Deliberative Democracy and the Discursive Dilemma
}

\section{Philip Pettit}

Taken as a model for how groups should make collective judgments and decisions, the ideal of deliberative democracy is inherently ambiguous. Consider the idealised case where it is agreed on all sides that a certain conclusion should be endorsed if and only if certain premises are admitted. Does deliberative democracy recommend that members of the group debate the premises and then individually vote, in the light of that debate, on whether or not to support the conclusion? Or does it recommend that members individually vote on the premises, and then let their commitment to the conclusion be settled by whether or not the group endorses the required premises? Is deliberative democracy to enforce the discipline of reason at the individual level, as in the first possibility, or at the collective level, as in the second?

Deliberative-democratic theory has not addressed this issue, perhaps because of an implicit assumption that it does not matter whether the discipline of reason is imposed at the individual or at the collective level. But that assumption is false and there is no excuse for neglecting the issue raised. The discursive dilemma of my title - a generalisation of the doctrinal paradox that has recently received attention in analytical jurisprudence - shows that the procedures distnguished can come apart. Thus deliberative democrats must make up their minds on where they stand in relation to the issue; they cannot sit on the fence.

This paper is an attempt to address the issue and look at the grounds on which it may be resolved. In the first section, I give a brief account of the ideal of deliberative democracy, as I understand it. In the second, I introduce the discursive dilemma with the help of some stylised examples and then in the third section I show why the issue that it raises is of relevance, theoretically and practically, to the deliberative-democratic ideal. How should deliberative democrats resolve that issue? I argue in the fourth section that the role in which republican theory casts deliberative democracy argues for preferring the imposition of reason, where possible, at the collective level. And then in the final section I argue for the 
consistency of that position with the main sorts of argument put forward by others in defence of the ideal.

\section{The ideal of deliberative democracy}

There are three issues on which deliberative democrats divide among themselves. First, the question of how many contexts - electoral, parliamentary, industrial, educational, and so on - ought to be democratised. Second, the question of how many issues in any democratised context ought to be under democratic control: just the choice of office-holders, or also the choice of policy-programs, or perhaps the choice of some detailed policies. And third, the question of how far a democratic character serves to justify or legitimate a regime and pattern of decisionmaking, or at least to give them a presumptive authority: to place the onus of argument on the shoulders of those who would not comply.

But there, or thereabouts, disagreement runs out. For no matter what their differences on such matters, deliberative democrats do show a remarkable degree of consensus on how democracy should be organised. Wherever democracy is instituted, however deeply democratic control runs, and whatever standing it is taken to give to decision-making, they agree that it ought to be inclusive, judgmental and dialogical (see the represeentative readings in Bohman and Rehg 1997; Elster 1998). These constraints spell out what I shall describe here as the deliberativedemocratic ideal.

- The inclusive constraint: all members are equally entitled to vote on how to resolve relevant collective issues, or bundles of issues, with something less than a unanimous vote being sufficient to determine the outcome.

- The judgmental constraint: before voting, members should deliberate on the basis of presumptively common concerns about which resolution is to be preferred.

- The dialogical constraint: they should conduct this deliberation in open and unforced dialogue with one another, whether in a centralised forum or in various decentralised contexts.

The inclusive constraint means that deliberative democracy is to be contrasted with elitist or authoritarian schemes, even ones in which deliberation and dialogue have an important place. It will be satisfied in any context by having a representative 
democracy, if democratic control only runs to the choice of office-holders, but the general assumption is that where direct participation by all members is feasible and is consistent with the general case for deliberative democracy - it will be preferred to indirect representation. The constraint includes the stipulation that unanimity is not required for the determination of an outcome by voting, since a combination of inclusiveness and unanimity would lead to a group's being unable to reach a common view on most significant issues; unanimity is probably achievable, at best, only on very abstract constitutional matters (Buchanan and Tullock 1962).

The judgmental constraint has got two sides to it. First, it requires voters to deliberate or reason about how they should vote, not just vote in an unreflective or spontaneous or reflex manner. And second, it requires voters to deliberate about how they should vote on the basis of considerations as to what is best for the society as a whole: what is likely to advance those common interests that people are capable of recognising as common interests. This constraint need not itself specify any particular conception of such common, perceived interests: that may itself be matter for the sort of deliberation recommended. What it counsels against is any pattern of voting in which each individual voter takes account only of what is good for his or her particular coterie or corner or circle. The model of voting recommended under this constraint can be described as judgment-voting rather than preference-voting (Cohen 1986; Coleman and Ferejohn 1986; Brennan and Pettit 1990). The idea is that each voter should make up his or her own mind as to what is for the good of the group in question and should vote on the basis of that judgment, not on the basis of brute preference (Sunstein 1993) or bargained compromise (Elster 1998, 5-8; cf Pettit 1993, Ch.5).

The third, dialogical constraint in the ideal of deliberative democracy marks a further, important level of differentiation. It rules out the sort of plebiscitarian dispensation in which each participant privately forms his or her judgment about common perceived interests, rather than doing so in dialogue with others, and then votes on the basis of that judgment. It is sometimes thought, on the basis of his remarks about the danger of faction, that Rousseau embraced this plebiscitarian ideal. According to Rousseau, so it is said, 'each voter is polled about his independently reached choice, without any group deliberation' (Grofman and Feld 
$1988,570)$. But this interpretation is almost certainly mistaken, if only because it makes no sense of Rousseau's requiring that the people come together in an assembly. What he was anxious to guard against was not dialogue and debate, with the formation of individual judgment that this fosters, but rather the threat of some individuals' being so intimidated or impressed by others - so deferential towards them - that they vote according to the judgments of those others, not according to their own (Estlund and Waldron 1989).

The third constraint requires that the dialogue envisaged be open and unforced, while allowing that it may be centralised or decentralised. It must be open in the sense that each can get a hearing and it must be unforced in the sense that no one need fear to speak their mind; it must approximate the conditions for ideal speech that Juergen Habermas $(1984,1989)$ emphasises. Some will insist that dialogue must be centralised in a single forum, if talk of deliberative democracy is to be justified (Goodin 1999). But I think that it is better to leave that question open and to take the centralised or collective picture of deliberative democracy as a more specific version of a broader ideal.

\section{The discursive dilemma}

So much for the different elements in the ideal of deliberative democracy. In this and the next section I want to show that the ideal is seriously underspecified and, in particular, that there are two quite different ways in which it may be understood in any context.

My argument in this section derives from the recent discussion in jurisprudential circles of what its analysts have sometimes called the doctrinal paradox (Kornhauser and Sager 1986; Kornhauser 1992; Kornhauser 1992; Kornhauser and Sager 1993. See too Chapman 1998a; Chapman 1998b; Brennan 1999). This is a paradox that arises when a multi-member court has to make a decision on the basis of received doctrine as to the considerations that ought to be taken into account: on the basis of a conceptual sequencing of the issues to be decided (Chapman 1998a) . I describe the problem, in its general form, as a discursive dilemma. I prefer the word 'discursive', because the problem in question is not tied to the acceptance of common doctrine, only to the enterprise of making 
group judgments on the basis of reasons. I prefer the word 'dilemma', because while the problem generates a choice in which each option has its difficulties, it does not constitute a paradox in any strict sense. My analysis of the discursive dilemma derives directly from that jurisprudential literature, though many of the points I want to make do not appear there; where they do appear, I explicitly acknowledge them.

The discursive dilemma: the conjunction case

In order to introduce the discursive dilemma, consider an issue that might arise in a workplace, among the employees of a company: for simplicity, as we may assume, a company owned by the employees. The issue is whether to forego a payrise in order to spend the money thereby saved on introducing a set of workplace safety measures: say, measures to guard against electrocution. Let us suppose for convenience that the employees are to make the decision - perhaps because of prior resolution - on the basis of considering two separable issues: first, whether the danger is serious: say, whether the risk of electrocution is above some tolerable threshold; and second, whether the pay-sacrifice would make it possible to buy a safety measure that would be effective in reducing the risk below that threshold, in the event of its having been above it. If an employee thinks that the danger is sufficiently serious, and the safety measure sufficiently effective, he or she will vote for the pay-sacrifice; otherwise they will vote against. And so each will have to consider the seriousness issue and the effectiveness issue and then look to what should be concluded about the pay-sacrifice.

Imagine now that after appropriate dialogue and deliberation the employees are disposed to vote on the relevant premises and conclusion in the pattern illustrated by the following matrix for a group of three workers. The letters A, B, and $\mathrm{C}$ represent the three employees and the 'Yes' or 'No' on any row represents the disposition of the relevant employee to admit or reject the corresponding premise or conclusion.

$\begin{array}{lccc} & \text { Serious danger? } & \text { Effective measure? } & \text { Pay-sacrifice? } \\ \text { A. } & \text { Yes } & \text { No } & \text { No } \\ \text { B. } & \text { No } & \text { Yes } & \text { No } \\ \text { C. } & \text { Yes } & \text { Yes } & \text { Yes }\end{array}$




\section{$\underline{\text { Matrix } 1}$}

If this is the pattern in which the employees are inclined to vote, then what decision or judgment will be made by the group under deliberatively democratic procedures? It turns out that a different decision will be made, depending on whether the group judgment is driven by how members judge on the premises or by how they judge on the conclusion. Looking at the matrix, we can see that though a majority rejects the pay-sacrifice, a majority supports each of the premises. If we think that the views of the employees on the conclusion should determine the groupdecision, then we will say that the group-conclusion should be to reject the paysacrifice: there are more 'No's' than 'Yes's' in the final column. But if we think that the views of the employees on the premises should determine the group-decision, then we will say that the group-conclusion should be to accept the pay-sacrifice: there are more 'Yes's' than 'No's' in each of the premise columns. The fact that socially aggregating the conclusion-judgments gives us a different result from socially aggregating the premise-judgments illustrates the discursive dilemma.

It should be clear that the discursive dilemma will generalise from the threeperson case to a group of any size. All that is required for the paradox to arise is that a majority in the group supports the first of the premises, a different majority supports the second - B and C rather than $A$ and $\mathrm{C}$ - and the intersection or overlap of those majorities $-\mathrm{C}$ in our example - represents only a minority in the group as a whole. The fact that the intersection represents only a minority explains why there is a majority against the conclusion. But not only will the paradox generalise to groups of any size. It should equally be clear that it will generalise in other ways too: for example, to a case where there are any number of premises, not just two; and to cases that arise in quite different domains.

The structure required for the sort of paradox illustrated to be capable of generalising can be summed up in these points:

a. there is a conclusion to be decided among a group of people by reference to a conjunction of independent or separable premises - the conclusion will be endorsed if relevant premises are endorsed, and otherwise it will be rejected; b. each member of the group forms a judgment on each of the premises and a corresponding judgment on the conclusion; 
c. each of the premises is supported by a majority of members but those majorities do not coincide with one another;

d. the intersection of those majorities will support the conclusion, and the others reject it, in view of a; and

e. the intersection of the majorities is only a minority in the group as a whole.

The discursive dilemma, as illustrated in our workplace example, stems from the fact that the group can make its judgments in the conclusion-driven way or in the premise-driven way and that in many cases those procedures yield different results. It constitutes a dilemma, so far as each option has its problems. As the example shows, going the conclusion-driven way means adopting a course that is inconsistent with the premises endorsed by the group and going the premise-driven way means adopting a course that a majority individually reject. Going the first way means sacrificing collective rationality for the sake of responsiveness to individuals, going the second means sacrificing responsiveness to individuals for the sake of collective rationality.

There are familiar practices of group deliberation and decision-making corresponding to those different approaches. Thus the group would go the conclusion-driven way if members entered into deliberation and dialogue and then each cast their personal vote on whether to endorse the pay-sacrifice or not; in that case the decision would be against the pay-sacrifice. The group would go the premise-driven way, on the other hand, if there was a chairperson who took a vote on each of the premises - say, a show of hands - and then let logic decide the outcome; in this case the decision would be in favour of the pay-sacrifice.

The discursive dilemma: the disjunction case

But the sort of discursive dilemma illustrated is not the only sort there is. Another version of the dilemma arises when the issue facing a group has to be decided, not by reference to a conjunction of premises, but rather by reference to a disjunction. In this case the conclusion will be endorsed if any one of the premises is endorsed - any, not all - and otherwise it will be rejected. (It might also be required, of course, that any two of three or more premises would have to be 
endorsed — or any three of four or more premises, and so on — but I shall ignore that possibility here.)

The second variety of the discursive dilemma can be illustrated with another sort of decision that our workplace group might face. Suppose that the group has to decide on whether to introduce a clocking-in and clocking-out system and that by their shared lights the decision should be made on the grounds, and only on the grounds, either that such a time-check would increase productivity or that it would serve to reassure everybody that others are pulling their weight in the joint enterprise. Let someone decide the productivity question in the affirmative, or let them decide the reassurance question in the affirmative, and their conclusion will be that the time-check should be introduced; otherwise they will conclude that it ought not to be introduced. The conclusion will be judged by reference to a disjunction of those independent premises: endorsing either premise on its own will be enough to support the endorsement of the conclusion; rejecting both of the premises will be enough to support the rejection of the conclusion.

Imagine now, as in the conjunction case, that after appropriate dialogue and deliberation the employees are disposed to vote on the relevant premises and conclusion in the pattern illustrated by the following matrix for a group of three workers. The letters A, B, and C represent the three employees, as before, and the 'Yes' or 'No' on any row represents the disposition of each to admit or reject the corresponding premise or conclusion.

Productivity issue? Reassurance issue?

$\begin{array}{llll}\text { A. } & \text { Yes } & \text { No } & \text { Yes } \\ \text { B. } & \text { No } & \text { Yes } & \text { Yes } \\ \text { C. } & \text { No } & \text { No } & \text { No } \\ & & \underline{\text { Matrix 2 }}\end{array}$

Where votes follow this pattern, then the premise-driven approach will yield one group-judgment, as in the previous sort of case, the conclusion-driven approach another. Each of the premises is rejected by a majority, as we can see by considering the premise columns, so that if we go by the premises, then we will take the groupdecision to be against the time-check proposal. But the conclusion, on the other hand, is endorsed by a majority so that if we go by the conclusions the employees 
individually reach, then we will take the group-decision to be in favour of the timecheck.

This sort of dilemma allows of generalisation in just the same way as the first. The salient points to preserve in this case mirror the points mentioned with the other: a. there is a conclusion to be decided among a group of people by reference to a disjunction of independent or separable premises - the conclusion will be endorsed if any of the premises is endorsed, and otherwise it will be rejected; b. each member of the group forms a judgment on each of the premises and a corresponding judgment on the conclusion;

c. each of the premises is supported by a minority of members but those minorities do not coincide with one another;

$\mathrm{d}$. the union of those minorities will support the conclusion, and the others reject it, in view of $\mathrm{a}$; and

e. the union of the minorities is a majority in the group as a whole.

In this case, as in the last, there are familiar decision-making practices that differ in implementing either a conclusion-driven mode of group-judgment or a premise-driven mode. The workplace ballot in which each casts his or her vote privately would implement the conclusion-driven mode, whereas the workplace meeting in which the chair takes a vote on each of the relevant considerations and then announces the significance for the conclusion would implement the premisedriven mode.

\section{The relevance of the dilemma for deliberative democracy}

The relevance in principle

Under the regime of deliberative democracy, it is required that with any logically connected propositions in the domain of discussion - the premises and conclusion of our examples - people make up their minds about the propositions in such a way that reason is satisfied. They do not endorse inconsistent or otherwise incoherent sets of propositions; they do not fail to derive conclusions that are supported, even saliently supported, by what they already endorse; and they do not follow a procedure - say, one of unanimitarian voting - that gives them nothing to say on most issues (List and Pettit 2000). 
The question raised by the discursive dilemma is whether this discipline of reason is meant to apply to each individual, taken singly, or to the group taken as a whole. Under the conclusion-driven, majoritarian way of voting the discipline is applied to each individual, under the premise-driven, majoritarian way of voting it is applied to the group taken as a whole. The question is a pressing one, where it arises, because it represents a hard choice or dilemma. Let a group individualise reason, and it will ensure responsiveness to individuals in its collective view on each issue but it will run the risk that the views will be irrational. Let a group collectivise reason, and it will ensure the rationality of the collective views maintained but run the risk of adopting a view on one or another issue that is unresponsive to the views of individuals on that issue.

The choice with which groups are faced is not necessarily a choice between following a conclusion-driven, majoritarian procedure and following a premisedriven, majoritarian one. Individualising reason and ensuring responsiveness to individual views will always involve having members vote, whether on a majoritarian or some other basis, about each of the issues involved, and then letting that vote determine the collective view; this, in effect, is a generalisation of the conclusion-driven procedure. But collectivising reason and ensuring collective rationality will not always involve privileging certain issues in the manner of premises and letting the collective views on those issues logically determine the collective view on the conclusion. Consistently with behaving in a deliberative democratic manner, the group might let the presumptive set of collective views be determined by having members vote on each issue and only consider moderating those views - amending one or other of them - in the event of the collective views proving to be irrational in some way. The amendment chosen might involve letting the views with the presumptive status of premises - if that can be agreed determine the view on the conclusion. But it might also involve holding onto that conclusion and revising the collectively endorsed view on one of the premises. In short, it might involve practising modus ponens - letting the premises dictate the conclusion - or modus tollens - keeping the conclusion and revising one or more of the premises. 
To sum up, then, the discursive dilemma is relevant in principle to deliberative democracy so far as it raises the question as to whether deliberative democrats require people to be disciplined by reason at the individual or, where this is feasible, at the collective level. There is a dilemma involved, because each of the options available has its problems. Let people be disciplined by reason at the individual level and they may collectively endorse an irrational set of propositions. Let them be disciplined by reason at the collective level and they may collectively endorse a conclusion that a majority of them individually reject.

The relevance of the dilemma in practice

But is the discursive dilemma relevant in practice to the way the ideal of deliberative democracy is specified? Some might say that it is not, on the grounds that it is rarely going to be a feasible option for people to discipline themselves by reason at the collective level and that all deliberative democracy can require is that individuals do this in the formation of their opinions at the individual level. The problem raised will be that if people are to discipline themselves collectively by reason, then they must agree on what are the relevant considerations by reference to which various issues are to be decided. But that agreement, so it will be said, is rarely going to be available. Thus sceptics will maintain that the assumption that the parties in my workplace examples agree on the premises by reference to which the paysacrifice and time-check issues are to be decided is an idealisation rarely satisfied in practice.

This point is well taken for large scale collectivities such as an electorate and it may well be the case that all deliberative democrats can seek in such contexts is a discipline of reason imposed at the individual level. ${ }^{1}$ But the point does not hold more generally. There are two sorts of groups that routinely confront the possibility of collective self-discipline, and that must therefore decide on whether to follow reason at the individual or at the collective level. And there is a further, more general consideration why any groups that seek to advance a common purpose, and not just the two sorts mentioned, are going to confront that possibility in the course of their development. 
The first sort of case is that of a group that is charged by an external authority with making certain decisions on the basis of designated considerations, and on that basis only. Examples of such groups are appointment and promotions committees; committees charged with deciding who is to win a certain prize or contract; trusts that have to make judgments on the basis of a trustee's instructions; associations or the executives of associations that have to justify their actions by reference to the group's charter; corporations that have to comply with policies endorsed by their shareholders; public bodies, be they bureaucratic committees or appointed boards, that have to discharge specific briefs; and governments that are more or less bound to party programs and principles. In all of these cases deliberative democrats will want their ideal to apply and in each case there will clearly be an issue as to whether the discipline of reason should be imposed at the individual or at the collective level.

In the second sort of case, it will be a matter of internal aspiration in a group that members find common grounds by which to justify whatever line they collectively take. Think of the political movement that has to work out a policy program; or the association that has to decide on the terms of its constitution; or the church that has to give an account of itself in the public forum; or the learned academy that seeks a voice in the larger world of politics and journalism. In such cases members of the group may not have access to an antecedently agreed set of considerations on the basis of which to justify particular judgments. But their identification with one another will support a wish to reach agreement on such a set of reasons. To the extent that that wish gets to be satisfied, the discursive dilemma will generate the issue as to whether the group should make its decisions in a premise-driven or conclusion-driven way.

These two cases are special in a certain way. They contrast with the case of a group that has to advance a purpose, as those groups have to do, but that may be quite happy to have its members reach a judgment on any issue without their agreeing on the reasons that support that judgment; a majority may vote for the judgment but, theorising it only incompletely (Sunstein 1999), different people within that majority may support it for different reasons. Will a group of this laidback kind ever confront the possibility of imposing reason at a collective level and ever have to face the discursive dilemma? I believe that it will (Pettit 2000). 
Like the other groups envisaged, this sort of group is bound to generate a history of judgments that it is on record as making, when it seeks to pursue its purposes. But those past judgments will invariably constrain the future judgments that it can rationally maintain at the collective level: this, in the way that a political party's past commitments on reducing taxes but increasing expenditure in certain areas will constrain the other decisions it has to make about expenditure. And so there will be a serious question for the group as to whether or not it should impose reason at the collective level, letting later judgments be dictated in a premise-driven way by earlier ones or disowning some of the earlier judgments; after all, the lesson of the discursive dilemma is that though every individual holds a rational set of views on the issues involved, voting independently on each issue could lead to a collectively irrational result. That question will arise to the extent that effective, joint action requires collectively rational judgments. And it will assume a particularly sharp form so far as members or outsiders are ready to charge the group, perhaps even mock it, for any failure of collective reason.

The upshot, then, is this. Take those groups where the ideal of deliberative democracy apparently applies and where the collectivisation of reason is not made infeasible by numbers or disorganisation. Are such groups likely to face the hard choice between individualising and collectivising deliberation? Yes, they are. They will certainly face that choice if they are commissioned to make their decisions on the basis of certain criteria or if they succeed in establishing criteria by which to make those decisions. But even if they do not have such criteria imposed on them, or cannot agree on any criteria by which to operate, they will still face the hard choice represented by the discursive dilemma; they will not be able to rest content with their members each voting according to their own particular reasons on the different issues that come before the group. The reason is that any such group will build up a history of judgments over time and those judgments are bound to provide reason, now here, now there, for taking a certain line on some new issue. Thus the group will have to choose either to let their line on this new issue be governed by majority vote, at a risk of proving inconsistent over time, or to enforce collective reason in the event of such inconsistency, whether by letting the previous judgments dictate that line or 
by allowing the new vote to stand and by revising one or more of those judgments. The discursive dilemma is, quite simply, unavoidable.

\section{The resolution in republican theory}

The republican argument for deliberative democracy

Republican theory, as I have argued elsewhere, puts a premium on people's enjoying freedom as non-domination: that is, on people's having a status such that ideally no one else is able to interfere arbitrarily in their lives. If any other person or agency is able to interfere in their lives, then they must be forced to track people's perceived interests in the interference they practise; they must not have a power of arbitrary interference.

That ideal raises the question of how the state can be blocked from enjoying a power of arbitrary interference in the lives of citizens. The state is a necessary institution and it necessarily has a power of interfering with people: it cannot operate without being able to tax, legislate and penalise the governed. So how is its power of interference to be made non-arbitrary? Republican constitutional theory is built around that question and has consistently sought to describe various devices whereby non-arbitrariness may be furthered. These include familiar mechanisms such as democratic election, rule of law, separation of powers, limitation of tenure, rotation of office, and so on.

In this republican tradition of constitutional discussion, one important strand has been the idea that if the state's power of interference is to be rendered nonarbitrary then whatever other devices are in place, people must be able to contest the decisions made by various arms of government. They must have access to the reasons supporting those decisions and they must be able to contest the soundness of those reasons or the degree of support they offer to the decisions made. Moreover they must be in a position, ideally, to expect that such contestations will be heard, will be impartially adjudicated and, if necessary, will be implemented against those in government. The general message is that so far as a government is effectively contestable, to that extent it is less likely to enjoy arbitrary power.

The effective promotion of contestability in the political sphere requires a variety of institutions, especially if it is to guard against unwieldy levels of 
complaint, and I have tried elsewhere to review some of them (Pettit 2000). From our point of view, however, only two observations are relevant. The first is that putting in place a regime of participatory or representative democracy is essential in guarding against certain possibilities of non-constestability and domination: the colonial, the authoritarian, and so on. And the second is that any such regime still leaves striking possibilities of non-contestability and domination in place: possibilities associated with the tyranny of the democratic majority, in particular, and the tyranny of what we might describe as the democratic elite: those in the corridors of power - for example, in the bureaucracy, the cabinet, the courts, the prisons, or the police force - who can impose their own will in how they interpret and implement democratic policy.

How are people to be empowered in relation to democratic majorities and democratic elites? How are they to be given a power of contestation against them? Whatever else is necessary, it seems clear that they must be able to ask after the reasons that support the decisions, they must be able to question the relevance of the reasons and they must be in a position to expect a fair hearing. And all of that is going to be possible, of course, only so far as the democratic bodies in question operate in a deliberative mode. There must be a dispensation of deliberation in place in the community as a whole, and in the microcosm of parliament, which establishes a currency of considerations that are admitted on all sides to be relevant to the doings of government. There must be a commitment in the different arms of government to justifying whatever decisions are taken by reference to the considerations that are relevant, by common consent, in their case. And it must be possible for private individuals, or perhaps for designated representatives, to challenge such decisions on the grounds that the reasons quoted are not sound or do not offer the requisite support for the decisions taken. It is only in the event of democracy having this deliberative cast that contestability, and ultimately nonarbitrariness, can be furthered.

This republican argument for deliberative democracy applies also, of course, to forums beyond those of government. Take the workplace community or the community organisation or indeed the family. Even if decisions are taken democratically in such a body, there will be little protection against arbitrariness - 
short of exit - unless the democracy in question operates in deliberative mode, giving individuals a chance to contest the decisions made. If decisions are made on the basis of interest-group politics, or bargaining from different levels of power, then there will be no grounds on which any contestation can be made. Brute force or naked preference will rule.

Cass Sunstein (1993) probably has this republican case for deliberativedemocratic procedure in mind when he describes deliberative democracy as a 'republic of reasons'. Just as people are in a position to know where they stand in relation to a court judgment, only so far as the judges have to provide statements of their reasons, so more generally people can know where they stand in relation to public decisions only if they know what the grounds adduced in support of those decisions are. They will not be able to take a stand in relation to public decisions, if those decisions are the outcome of interest-group bargaining or of voting on the basis of naked, unargued preference. Such non-deliberatively generated decisions would have the profile of dictats or fiats from on high, where the products of deliberativedemocratic procedure would present themselves as reasoned - well-reasoned or badly-reasoned - judgments that people are in a position to examine, assess and if necessary, challenge.

Applying the republican argument

The contestability argument for deliberative democracy ought to have persuasive force, quite apart from its connection with republican theory (see Pettit 2000). It is of particular interest here because - unusually among such arguments, as we shall see in the next section - it provides a firm ground for wanting, where that is feasible, to impose the discipline of reason at the collective, not at the individual, level.

If I am to be able to judge the actions of another individual or agency in relation to alleged reasons - and, ultimately, if I am to be able to contest those actions in the relevant sense - then the individual or agency must prove answerable to those reasons. The individual or agency must be disposed to act as the reasons require or, at the least, to adjust in response to the criticism that the reasons adduced in support of something they did are not appropriate or that what they did was not 
supported by those reasons. In a word, the individual or agency must prove to be conversable: that is, must prove to be an interlocutor whose words can be taken at face value and, where appropriate, invoked in effective criticism of the things they later do.

A group that records its assent to certain considerations on the basis of majority vote and which then proceeds to make its judgments and decisions according to the premise-driven strategy will prove conversable in this sense. Its judgments, decisions and actions will track those reasons in the ordinary case. And where they do not, or where the reasons adduced are shown to be in some way inappropriate, then it can be called effectively to book. The group will acknowledge a role for the consideration of reasons or premises in relation to any case; it will decide the group commitments in regard to those reasons or premises on the basis of majority vote, or some such measure of social aggregation; and it will then accept that how it judges or decides on the case in hand should be answerable to those commitments. You can deal with such a group as you might deal with an individual person; indeed the group will deserve to be regard as a legal or at least cultural person: a unified, corporate entity.

A group that makes its judgments and decisions on the basis of individualising reason, however, will have a very different profile. What the discursive dilemma reveals is that such a group may reach theoretical and practical conclusions that are completely out of kilter with the majority disposition of its members in relation to related propositions. There will be little or no point in interrogating the group for its view, under majority rule, of the different premises that might be thought to be relevant, for example, and might be acknowledged as relevant by members of the group. For it will be a permanent possibility that the conclusion it reaches is not the conclusion that those majority views would deliberatively support.

Consider the workforce in our earlier example. We might discover that the majority view among its members is that electrocution is a serious danger, and that a pay-sacrifice would solve the problem - and that those premises imply that a paysacrifice would be desirable; and yet it should be no surprise to find that the group comes down against a pay-sacrifice. There is no talking to a group that operates like 
this. It is inherently unconversable. Where the group that runs by premise-driven judgment and decision is a unified, corporate entity, the group envisaged here would be a disparate, aggregate sort of thing. It would not be one, but many.

Consider an analogy. Imagine that I am composed of many different personalities, as in some sense I undoubtedly am. There is the ecologically minded self, the economically minded self, and the socially minded self that likes to keep up with the neighbours. And now suppose that I face a decision about whether to buy a Volvo. That decision, let us say, will be determined by the views I take on two issues: one, whether to get a car; and two, whether the best car for someone like me to buy, asssuming they do buy a car, is a Volvo. It is quite possible, that faced with a decision like this, my different selves will go quite different ways. My economic self, A, may say that a car is desirable, but not a Volvo: it's too expensive. My ecological self may say that a car is undesirable but agree that a Volvo is the best sort of car to buy: it is environmentally the friendliest kind available. And my social self may hold that it would be good both to buy a car, in order to keep up with the neighbours, and that from this point of view a Volvo is the best sort there is. This, then, is the pattern of voting among my selves.

Car desirable? Volvo a desirable car? Get a Volvo?

$\begin{array}{llll}\text { Self A. } & \text { Yes } & \text { No } & \text { No } \\ \text { Self B. } & \text { No } & \text { Yes } & \text { No } \\ \text { Self C. } & \text { Yes } & \text { Yes } & \text { Yes } \\ & & \underline{\text { Matrix 3 }}\end{array}$

Constituted though I am in such a multiplex mode, I would pass as a unified, conversable agent were I to make my judgments and decisions in this and similar cases on a premise-driven basis. I would decide to buy a Volvo in the case on hand, reporting as I presumably would do that I think a car desirable and that I view a Volvo as the most desirable car there is; after all, those are the views defended by a majority of my selves. But imagine that I made my judgments and took my decisions in a way that individualised reason in my different selves, rather than collectivising it in my person as a whole. I would decide in a case like this not to buy a Volvo. And yet, interrogated about the relevant reasons - reasons that I myself might declare to be relevant - I would be found to defend considerations supporting the purchase of 
a Volvo. It should be clear that did I operate in this way, then I could not prove to be a conversable subject. I would be taken at best as a multitude of disorganised voices, at worst as someone without anything recognisable as a mind.

Might the demands of contestability be satisfied to the extent that the individuals in a group, though not the group itself, are conversable and contestable agents? Might they be satisfied in the way in which they are satisfied by the multijudge court? In this case, the group is relatively small and the differing individuals or subgroups give their differing reasons for taking their different lines, or indeed their differing reasons for taking the same line. It is not clear how satisfactory a model the judicial bench offers, given evidence that members switch votes in order to avoid problems and given recent critiques of the system (Kornhauser and Sager 1993; Stearns 1999). But those issues aside, I think that there are good reasons why contestability should be secured at the level of the group, not at the level of the different individuals who comprise it.

The group is the entity that continues over time despite changes in its membership, and that fact alone makes it the salient agency that we should want to be contestable and conversable. And not only does the group continue in time across changes in membership. It will often have so many members that no one could hope to secure contestability at the individual level. It will often be, not just the salient agency to make contestable, but the only feasible one available for that role.

These considerations of salience and feasibility are supported by a thought that would apply, even in their absence. It is only under a regime of group-level contestability that the relevant judgments will be made in a way that answers to reasons alone and that can be challenged on the basis of reasons alone. Where a group makes its judgments in the conclusion-driven way, there are two distinct factors that determine what judgment it makes in a given case: one, the reasons that receive majority support among members of the group; and two, the degree of overlap between the supporting majorities. But the second factor is not relevant from the point of view of contestability and so it is better for the group to give authority to the first factor only, as it does under the premise-driven procedure and, more generally, under any procedure that collectivises deliberation. 
Finally, a word in defence of sticking with this collectivising procedure, even in cases where its results may be counter-intuitive. Imagine that a court has to make a decision on whether or not someone should be given a retrial; that a retrial is required either in the event of inadmissible evidence having been used previously or in the event of the appelants's having been forced to confess; and that the voting goes as follows among three judges (Kornhauser and Sager 1993,40).

Inadmissible evidence? Forced confession?

Retrial?

$\begin{array}{llll}\text { A. } & \text { Yes } & \text { No } & \text { Yes } \\ \text { B. } & \text { No } & \text { Yes } & \text { Yes } \\ \text { C. } & \text { No } & \text { No } & \text { No }\end{array}$

Matrix 4

It is plausible in such a case that the person ought to be given a retrial, despite the fact that a majority rejects each of the relevant grounds. Does this suggest that there is a general problem of plausibility attached to premise-driven procedure? I think not.

While it is certainly implausible in such a case that the defendant should be denied a retrial, that implausibility can easily be registered in the approach of a group that seeks to collectivise deliberation. The implausibility can be taken by the group to indicate that the majority vote in favour of a retrial is more compelling than either premise-vote and that one or more of the premise-votes should be revised. Or the group may think that there is only one proposition which they each have to make a judgment on: viz., the disjunctive claim that there was inadmissible evidence or a forced confession. Or the implausibility may prompt members of the group to argue that while the representation in Matrix 4 is fine, what collective deliberation should be designed to secure in such a case is primarily the avoidance of a false negative denying a retrial to a deserving appelant - and that only a unanimously rejected ground of appeal should be dismissed by the group. Under any of these interpretations, the collectivising procedure would enable the group to grant a retrial. $^{2}$

\section{This resolution and other arguments for the ideal}


There are many different arguments in support of deliberative democracy to be found in the recent literature. The question that we must consider, then, is whether the position taken in favour of the premise-driven version of the ideal and, more generally, in favour of the version that collectivises deliberation - runs seriously counter to any of those other arguments. I devote the final section to that issue.

Arguments for making democracy deliberative

Most of the arguments in the literature focus on the virtue of making democracy deliberative: that is, on the benefit to a democratic process or society of having deliberation of an inclusive, dialogical kind (see Cohen 1989; Dryzek 1990; Sunstein 1993; Benhabib 1994; Gutmann and Thompson 1996; Bohman and Rehg 1997; Elster 1998). Some assert that making democracy deliberative should help to ensure that people's preferences are reflective and informed, not just the brute product of their adaptation to circumstance (Sunstein 1993); or that it should enable people to do better in reaching beyond the chasms of difference that separate the members of certain groups, even if it does not bring them into consensus (Young 1990); or that it should stretch people's imagination and empathy as they are forced to take a general point of view (Goodin 1999). Without alleging any such psychological transformation, other arguments maintain that making democracy deliberative should at least have the effect of screening out self-regarding concerns in favour of more public-spirited considerations, thereby approximating or advancing an ideal of public reasoning among free and equal participants (Habermas 1984, 1989; Elster 1986; Cohen 1989; Elster 1998). And yet a further range of arguments urge that making democracy deliberative would promote such effects as legitimising whatever decisions are reached, making them more likely to take account of the relatively powerless, increasing transparency among members of the group, or promoting just outcomes (see Elster 1998, 11, for a summary).

There is no likelihood that any arguments of this kind could be invoked against the view that deliberative democracy ought to impose reason at the collective rather than the individual level. We do not eliminate deliberation by making deliberative democracy premise-driven, for example, and thereby imposing reason at the collective level, and benefits of the kind invoked in these arguments all look to be 
consistent with such a procedure. Consider the case of the workforce deliberating on whether to introduce a safety measure or to establish a time-check. Even if they agree to reach a decision in a premise-driven way, they will first be required under the deliberative-democratic ideal to discuss the matter in public. And the benefits that come of making democracy deliberative, according to the arguments under consideration, would all seem to be available under the premise-driven way of doing things; in particular, they would seem to be available as readily and as richly as under the alternative. The premise-driven procedure makes ample room for achieving the psychological and other transformative effects mentioned in the arguments in question. And so of course would any other procedure that collectivised reason in a democratic way: say, as mentioned earlier, a procedure that allowed modus tollens as well as modus ponenes.

Not only that. Among such benefits there are some that look much more likely to be realised under a reason-collectivising procedure. With many democratic bodies, it is important by our general lights that members not be prejudiced in the conclusion they draw, for example, and not be lazy about the consideration they give to relevant premises. But if they are allowed to vote their individual judgments on the conclusion to be decided, then there is more room for prejudice and laziness than would be available under a collectivising procedure. Not having to give their judgment on the relevant premises, members of the body may find it easier to hide the influence of prejudice on their views. And not having to give their judgment on each premise, members may be tempted, once they have made a premise-judgment that determines their conclusion-vote, not to bother giving consideration to the other premises relevant.

Arguments for making deliberation democratic

But there is another sort of argument for the ideal of deliberative democracy that raises a sharper challenge to the republican position. This is the type of argument that makes a case, not for having deliberation present in democratic process, but rather for having democracy present in deliberative process; it argues for making deliberation democratic, not for making democracy deliberative. The claim is that if there are matters of truth involved in political deliberation - as in the question, most abstractly, of whether this or that is in the common interest - then 
the chance of reaching the truth, or of reaching the truth according to received views of reliability, is increased by having in place a regime of democratic decision-making. The argument may be recast for goals other than that of maximising the chance of reaching the truth or minimising the chance of falsehood. It applies just as readily to a more specific goal like that of minimising the chance of a false negative, for example: say, minimising the chance of finding an innocent defendant guilty. But I shall restrict myself here to the original truth-centred case.

This type of argument has been forcefully defended by David Estlund (1993a;1993b; 1997) but the most famous version, and the one I shall consider here, derives from the Marquis de Condorcet's work in defence of his so-called jury theorem (Black 1958; Condorcet 1976, 33-70; Estlund 1994). The theorem presupposes that the voters are independent of one another: while they may certainly form their opinions on the basis of dialogue, none of them votes in a way that is blindly deferential to others (Estlund and Waldron 1989; Estlund 1994). It shows that if voters each have the same, greater than evens chance of being right on some yes-no issue then, first, their collective resolution of the issue, under majority rule, will have a yet greater chance of being right and, second, it will have a progressively greater chance of being right as the size of the group increases. Indeed the latter element is assured, even if some voters have a less than evens chance of being right; it will hold so long as the average chance of voters being individually right is greater than evens (Owen, Grofman and Feld 1989).

Let competence in a person be identified with the probability that on being forced to choose between the answers, they will choose the right one. Suppose that the person has to choose, then, between judging that $\mathrm{p}$ and judging that not $\mathrm{p}$. Their competence will be given by the probability associated with its being the case: either that $p$, and they judge that $p$; or that not $p$, and they judge that not $p$. The message of the jury theorem is that if the the competence of individual voters is greater than $1 / 2$, then the competence of the group operating under majority rule will be greater still and will approach 1.0 as the number of members increases.

We cannot go through the proof of the jury theorem here - for an excellent presentation, see Estlund (1994) - but the idea is reasonably intuitive. Suppose that each of us in a certain group has a two thirds chance of being right on some sort of 
issue. If I provide an answer on my own as that sort of issue comes up instance after instance, then in the long run I may expect to be right two thirds of the time. But if three of us, A, B and C, decide what to say instance by instance, on the basis of a majority vote, then under the standard probability calculus (Skyrms 1966, 111-37), our performance ought to be better than mine on my own.

Here, in brief, is why. On any occasion the group will be right so long as at least two of us - so long as three of us or any two of us - are right. If the chance of any one of us being right on a given occasion is two thirds, then the chance of at least two of us being right is the chance that $A$ and $B$ but not $C$ are right, or that $A$ and $C$ but not $\mathrm{B}$ are right, or that $\mathrm{B}$ and $\mathrm{C}$ but not $\mathrm{A}$ are right, or that $\mathrm{A}$ and $\mathrm{B}$ and $\mathrm{C}$ are right. The chance that $\mathrm{A}$ and $\mathrm{B}$ but not $\mathrm{C}$ are right - assuming independence - is the chance of $A$ being right times the chance of $B$ being right times the chance of $C$ not being right: i.e. $2 / 3 \times 2 / 3 \times 1 / 3$, or $4 / 27$; and similarly for the other pairs. The chance that $A$ and $B$ and $C$ are all right is $2 / 3 \times 2 / 3 \times 2 / 3$, i.e. $8 / 27$. And so, the chance that at least two of us are right is the sum of these four figures: $4 / 27$ plus $4 / 27$ plus 4/27 plus 8/27; with disjuncts that are mutually incompatible the probability of the disjunction is the sum of the disjunct-probabilities. Thus the chance that at least two of us are right on any occasion is 20/27; and this is higher than the two thirds chance - 18/27 - of any one of us being right. The reasoning continues in the same way for each increase in the size of the group, supporting the Condorcetian conclusion that group competence approaches 1.0 as the size of the group increases.

The question now is whether the jury theorem provides any reason for resisting a mode of democratic judgment-making that imposes reason at the collective level. Is there a general argument for thinking that it is better, in Condorcetian terms, to collectivise reason rather than individualising it? In particular, to make the issue more specific, is there a general argument for going the premise-driven rather than the conclusion-driven way? As the answer goes in this case, so it should go more generally.

I raise the question under the assumption that a conclusion in the conjunctive case will be supported if the premises are supported and will be rejected otherwise. This is the assumption, in effect, that if the premises are ' $p$ ' and ' $q$ ', then the conclusion is just the conjunction of those premises. We need only consider the 
conjunctive case, since under our interpretation the chance of an individual or group being right about a disjunction, $\mathrm{p}$ or $\mathrm{q}$, is just the chance of their being right about the conjunction, not(not $\mathrm{p}$ and not $\mathrm{q})$.

The calculation of the relevant probabilities is a complex matter that Wlodek Rabinowicz and I address in an appendix, but the overall picture suggested by those calculations - suggested, not definitively established — is relatively clear. The premise-driven approach does better, according to that picture, provided we focus on the case where the individual or group is right about the conclusion through being right about the premises: provided they are right about the conclusion for the right reasons. But it is possible for an individual or group to be right about whether a conjunctive conclusion obtains, while being wrong about some or all of the conjunctpremises: it is possible to be right about the conclusion for the wrong reasons.

Suppose that it is not the case that $\mathrm{p}$ and $\mathrm{q}$. I may be right in thinking that it is not the case that $p$ and $q$ through thinking that not $p$ and $q$, or not $p$ and not $q$, when it is rather the case that $\mathrm{p}$ and not $\mathrm{q}$; or I may be right through thinking that $\mathrm{p}$ and not $\mathrm{q}$, or not $\mathrm{p}$ and not $\mathrm{q}$, when it is rather that case that not $\mathrm{p}$ and $\mathrm{q}$; or, finally, I may be right through thinking that $\mathrm{p}$ and not $\mathrm{q}$, or not $\mathrm{p}$ and $\mathrm{q}$, when it is rather the case that not $\mathrm{p}$ and not $\mathrm{q}$. It turns out, surprisingly, that if it does not matter what the reasons are for which an individual or group is right about a conclusion, then the conclusiondriven approach does better in Condorcetian terms: it offers a better chance of the group's making the correct judgment on the conjunctive conclusion.

How should we respond to this finding? It is not the most welcome result possible from the point of view of the argument in the last section; the most welcome result would have been that the premise-driven approach is better either way. But it is much more welcome than would have been the result that the conclusion-driven approach is better either way. And it is a result that, on reflection, proves to be quite congenial.

When a person or community makes a correct judgment that $\mathrm{p}$ for the wrong deliberative reasons, then we deny that they understand why it is the case that $p$, or that they know that $p$. But the ideal of deliberative democracy, as that has been articulated on all sides, is closely bound to the alleged prospect of an increase of understanding and perhaps knowledge on the part of individuals in the community, 
and the group as a whole; there is no suggestion that it merely increases the likelihood of serendipitous error. The ideal supposes that in relying on deliberation to guide them towards a collective judgment, people will be guided by right reasons: that is, by reasons that are sound as well as supportive.

This line of thought suggests that when we try to determine how satisfactory the premise-driven approach is in Condorcetian terms, the question we should ask is whether it does better than the conclusion-driven approach in promoting the chance of the group's getting the right result, assuming that the result is to be reached on the basis of right reasons. And the answer to that question, happily, does go the way of the premise-driven approach. Not only does the approach make contestability possible and so answer to republican concerns. Under the assumption that judgments are to be reached via right reasons, which is common to all theorists of deliberative democracy, it also holds out the best prospect of enabling the group to get at the truth.

I said that the picture defended in the appendix, on which we have been relying, is not definitively established there. What is worth noting, however, is that the less secure element in that picture is the suggestion that the conclusion-driven approach will do better when it does not matter whether the moving considerations are the right reasons or not. The claim that the premise-driven procedure will do better than the conclusion-driven when only right reasons are in play - that is, the claim on which the validity of the comments just made depends - looks to be much more firmly supported.

I conclude, to return to the general line, that the various arguments in the literature for deliberative democracy are consistent with the republican way of resolving the question that the discursive dilemma raises. The republican concern with contestability gives powerful reason for wanting democratic procedure to be deliberative, where possible, in way that imposes the discipline of reason at the collective level. And the other considerations that are more generally invoked to support deliberative democracy do not represent countervailing forces. ${ }^{3}$

Research School of Social Sciences, Australian National University, Canberra, ACT 0200 


\section{References}

Philip.Pettit@anu.edu.au.

Benhabib, S. (1994). "Deliberative rationality and models of democratic legitimacy." Constellations 1: 26-52.

Black, D. (1958). The Theory of Committees and Elections. Cambridge, Cambridge University Press.

Brennan, G. (1999). Collective Irrationality and Belief. Canberra, Research School of Social Sciences, Australian National University.

Brennan, G. and P. Pettit (1990). “Unveiling the Vote.” British Journal of Political Science 20: 311-33.

Buchanan, J. and G. Tullock (1962). The Calculus of Consent. Ann Arbor, University of Michigan Press.

Chapman, B. (1998). “Law, Incommensurability, and Conceptually Sequenced Argument." University of Pennsylvania Law Review 146: 1487-1582.

Chapman, B. (1998). “More Easily Done than Said: Rules, Reason and Rational Social Choice." Oxford Journal of Legal Studies 18: 293-329.

Cohen, J. (1986). “An Epistemic Conception of Democracy.” Ethics 97: 26-38.

Cohen, J. (1989). Deliberation and Democratic Legitimacy. The Good Polity. A. Hamlin and P. Pettit: 17-34.

Coleman, J. and J. Ferejohn (1986). “Democracy and Social Choice.” Ethics 97: 6-25.

Condorcet, M. d. (1976). Condorcet: Selected Writings. Indianopolis, Bobbs-Merrill.

Dryzek, J. S. (1990). Discursive Democracy. Cambridge, Cambridge University Press. Estlund, D. (1993). Making Truth Safe for Democracy. The Idea of Democracy. D. Copp, J. Hampton and J. E.Roemer. Cambridge, Cambridge University Press: 71-100.

Estlund, D. (1993). “Who's Afraid of Deliberative Democracy?" Texas Law Review 71: 1437-77. 
Estlund, D. (1994). “Opinion Leaders, Independence, and Condorcet's Jury Theorem." Theory and Decision 36: 131-62.

Estlund, D. (1997). Beyond Fairness and Deliberation: The Epistemic Dimension of Democratic Authority. Deliberative Democracy: Essays on Reason and Politics. J. Bohman and W. Rehg. Cambridge, Mass., MIT Press.

Estlund, D. and J. Waldron (1989). “Democratic Theory and the Public Interest: Condorcet and Rousseau Revisited." American Political Science Review 83: 1317-1328.

Goodin, R. E. (1999). Democratic Deliberation Within. Canberra, Research School of Social Sciences, Australian National University.

Grofman, B. N. and S. Feld (1988). “Rousseau's General Will: A Condorcetian Perspective." American Political Science Review 82: 567-76.

Gutmann, A. and D. Thompson (1996). Democracy and Disagreement. Cambridge, Mass, Harvard University Press.

Habermas, J. (1984, 1989). A Theory of Communicative Action, Vols1 and 2. Cambridge, Polity Press.

Kornhauser, L. A. (1992). “Modelling Collegial Courts. I. Path-Dependence." International Review of Law and Economics 12: 169-85.

Kornhauser, L. A. (1992). “Modelling Collegial Courts. II. Legal Doctrine.” Journal of Law, Economics and Organization 8: 441-70.

Kornhauser, L. A. and L. G. Sager (1986). “Unpacking the Court.” Yale Law Journal 82.

Kornhauser, L. A. and L. G. Sager (1993). “The One and the Many: Adjudication in Collegial Courts." California Law Review 81: 1-59.

List, C. and P. Pettit (2000). The Aggregation of Reason: An Impossibility Result. Canberra, Australian National University.

Owen, G., B. Grofman, et al. (1989). "Proving a distribution-free generalization of the Condorcet jury theorem." Mathematical Social Sciences 17: 1-16. 
Pettit, P. (1997). Republicanism: A Theory of Freedom and Government. Oxford, Oxford University Press.

Pettit, P. (2000). “Democracy, Electoral and Contestatory.” Nomos.

Pettit, P. (2000). Groups with Minds of their Own. Canberra, Australian National University.

Skyrms, B. (1966). Choice and Chance: An Introduction to Inductive Logic. Belmont, Cal., Dickenson.

Stearns, M. L. (1999). “Should Justices Ever Switch Votes? Miller v. Albright in Social Choice Perspective." Supreme Court Economic Review 7: 87-156.

Sunstein, C. (1999). One Case At A Time. Cambridge, Mass, Harvard University Press.

Sunstein, C. R. (1993a). The Partial Constitution. Cambridge, Mass., Harvard University Press.

Young, I. M. (1990). Justice and the Politics of Difference. Princeton, Princeton University Press.

\section{Appendix. The jury theorem and the discursive dilemma \\ Background \\ Philip Pettit and Wlodek Rabinowicz}

Let us assume that in a society, $\mathrm{S}$, everyone has a greater than evens chance, $k$, of being right in respect of each of two unrelated propositions, $\varphi$ and $\psi$. This, to take the case of $\varphi$ in illustration, means that for any member, $x$, the probability that $x$ judges that $\varphi$, and $\varphi$, or that $x$ judges that not $\varphi$, and not $\varphi$, is greater than $1 / 2$. If we use $R_{\varphi}$ for 'is right in respect of $\varphi^{\prime}$, i.e., as short for the underlined proposition in the preceding sentence, then we can express the assumption by saying that for every $x$ and $y$ in $S, P\left(R_{\varphi} x\right)=P\left(R_{\varphi} y\right)=k>1 / 2$; and similarly for $\psi$.

Let us assume, in addition, that the chance of any individual's being right about one of the propositions is independent of the chance of any other 
individual's being right about it. Thus for all $x$ and $y$ in $S, P\left(R_{\varphi} x \& R_{\varphi} y\right)=$ $P\left(R_{\varphi} x\right) \cdot P\left(R_{\varphi} y\right)$, and similarly for $\psi$.

Under these assumptions, the Condorcet jury theorem gives rise to an interesting question. We know from the theorem that given the two assumptions, the probability of a majority's being right about either proposition is greater than $\mathrm{k}$ and that it approaches 1 as the size of the group increases. But what is the probability of a majority's being right about the conjunction $\varphi \& \psi$ ? That question divides into two, in the light of the discursive dilemma. First, what is the probability of a majority's being right, if the group follows the premisedriven procedure? And second, what is the probability of a majority's being right, if the group follows a conclusion-driven procedure?

We explore the answers to these questions in this appendix, entering specific values for the size of the group and for the chance of an individual's being right about a proposition. In pursuing this exploration we add some further assumptions, in order to make the questions tractable. We take it, not only that $\varphi$ and $\psi$ are unrelated propositions in respect of content, but also that the competence of each individual in respect of those propositions is unrelated. Thus, the probability that the individual correctly judges one proposition to be true or false is independent both of the truth value of the other proposition and of his judgment of that proposition (Independence). We assume that each individual is opinionated with respect to both $\varphi$ and $\psi$, i.e., the probability that he judges $\varphi(\psi)$ to be true or to be false - the probability that he judges that it holds or judges that it does not hold - equals 1 (Opinionation). We assume also that, for each of these propositions, its being true is equiprobable with its being false (Equiprobability of Propositions). And we assume that the competence of each individual is evenhanded as far as each proposition and its negation are concerned: that he judges it to be true and it is true is just as probable as that he judges it to be false and it is false (Evenhandedness).

A complexity: being right for the wrong reasons

These questions involve a complexity that is not at first obvious. If we ask about someone's - or indeed some group's - chance of being right about a 
conjunction like $\varphi \& \psi$ then we have to consider the chance of their being right in each of four (as we assume, equiprobable) scenarios:

1. $\varphi \& \psi 2$. $\operatorname{not} \varphi \& \operatorname{not} \psi$. 3. $\varphi \& \operatorname{not} \psi 4$. not $\varphi \& \psi$.

In each of those scenarios we have to determine the chance of the person's being right for the right reasons, i.e. through being right about each of the conjuncts; or being right for the wrong reasons, i.e. through being wrong about one or even both of the conjuncts. A person can be right in scenario 1 only through being right about both conjuncts; in 2 through being right about both or wrong about one and right about the other; in 3 through being right about both, through being wrong about both, or through being wrong about the first and right about the second; and in 4 through being right about both, through being wrong about both, or through being right about the first and wrong about the second.

\section{First question, re premise-driven procedure}

Let us now consider the first question. Specifically let us consider it under the assumption that we have a group, $S$, of just three members and that the chance, $\mathrm{k}$, of an individual's being right is $2 / 3$. Under the premise-driven procedure we first have to determine the chance of the group's being right about each of the propositions, $\varphi$ and $\psi$. The Condorcet jury theorem, applied as illustrated in the text, tells us that this chance is $20 / 27$. So what, then, is the chance of the group's being right about the conjunction $\varphi \& \psi$ ?

The elements required for making this calculation are presented in this table, where ' $\mathrm{J}$ ' indicates that the proposition following is judged to be true by the relevant subject: in this case, the majority and so the group.

Scenarios Ways of being right

1. $\phi$ and $\psi$ $\mathrm{J} \phi$ and $\mathrm{J} \psi$

2. not $\phi$ and not $\psi$ Jnot $\phi$ and Jnot $\psi$

Jnot $\phi$ and J $\psi$

J $\phi$ and Jnot $\psi$
Chance of being right $20 / 27 \times 20 / 27$

Total: $400 / 729$

$20 / 27 \times 20 / 27$

$20 / 27 \times 7 / 27$

$7 / 27 \times 20 / 27$ 
Total: $680 / 729$

3. $\phi$ and not $\psi$

$$
\begin{aligned}
& \text { J } \phi \text { and Jnot } \psi \\
& \text { Jnot } \phi \text { and Jnot } \psi \\
& \text { Jnot } \phi \text { and J } \psi
\end{aligned}
$$

$20 / 27 \times 20 / 27$

$7 / 27 \times 20 / 27$

$7 / 27 \times 7 / 27$

Total: $589 / 729$

4. not $\phi$ and $\psi$

$$
\begin{aligned}
& \text { Jnot } \phi \text { and } \mathrm{J} \psi \\
& \text { Jnot } \phi \text { and Jnot } \psi \\
& \text { J } \phi \text { and Jnot } \psi
\end{aligned}
$$

$20 / 27 \times 20 / 27$

$20 / 27 \times 7 / 27$

$7 / 27 \times 7 / 27$

Total: $589 / 729$

The table displays the fact that it is harder for the group to be right in scenario 1 about the conjunction than in other cases; in those cases the group can be right about the conjunction while being wrong about one or both of the conjuncts. The overall probability of the group's being right about the conjunction will equal the sum of the four totals, divided by 4 , since the scenarios are equiprobable. And that figure comes out as 1129/1458. This is the chance of the group's being right about the conclusion, for right or wrong reasons, under the premise-driven procedure.

But what is the chance of the group's being right for the right reasons? The answer is given by the sum of the first row totals for the four scenarios, divided by 4 . And the figure in this case is $400 / 729$ : i.e. $800 / 1458$ as against $1129 / 1458$.

\section{Second question, re conclusion-driven procedure}

Now for the second question, which bears on the group's chance of being right in the event of following a conclusion-driven procedure. Here the first calculation involves the random individual's chance of being right about the conjunction, given an independent $2 / 3$ rds chance of being right about any conjunct. The elements required in this calculation are given in the following table:

Scenarios

Ways of being right

Chance of being right 
1. $\phi$ and $\psi \quad J \phi$ and $J \psi \quad 2 / 3 \times 2 / 3$

Total: $4 / 9$

2. not $\phi$ and not $\psi J$ not $\phi$ and Jnot $\psi$

$2 / 3 \times 2 / 3$

$$
\begin{aligned}
& \text { Jnot } \phi \text { and } \mathrm{J} \psi \\
& \mathrm{J} \phi \text { and Jnot } \psi
\end{aligned}
$$

$2 / 3 \times 1 / 3$

$1 / 3 \times 2 / 3$

Total: 8/9

3. $\phi$ and not $\psi$

$$
\begin{aligned}
& \text { J } \phi \text { and Jnot } \psi \\
& \text { Jnot } \phi \text { and Jnot } \psi \\
& \text { Jnot } \phi \text { and J } \psi
\end{aligned}
$$

$2 / 3 \times 2 / 3$

$1 / 3 \times 2 / 3$

$1 / 3 \times 1 / 3$

Total: 7/9

4. not $\phi$ and $\psi$

Jnot $\phi$ and $\mathrm{J} \psi$

$2 / 3 \times 2 / 3$

Jnot $\phi$ and Jnot $\psi$

$2 / 3 \times 1 / 3$

J $\phi$ and Jnot $\psi$

$1 / 3 \times 1 / 3$

Total: 7/9.

What is the chance of a random individual's being right about the conjunction for any reasons, right or wrong? This is given by the sum of the four totals, divided by 4 , which is $13 / 18$. And what in that case, using Condorcet's theorem, will be the chance of a majority being correct? This will be the sum of the chances attaching to the possibilities that all three members are correct, that the first two are correct and the third wrong, that the first and third are correct and the second wrong, and that the second and third are correct and the first wrong. And that works out at 1183/1458. This is somewhat greater than the chance of the group's being right, no matter for what reasons, under the premisedriven approach: 1183/1458 as against 1129/1458.

What is the chance of the group's being right when the individuals are right for the right reasons? In order to get an individual's chance of being right for the right reasons about the conjunction, we need to go back to the calculation for the random individual, add up the first row totals for each scenario, and divide by 4 . 
This gives us a figure of 4/9. Using the now familiar Condorcetian calculation, we then find that the chance of a majority being right about the conclusion is $648 / 1458$. This is considerably smaller than the chance of the group's being right for the right reasons under the premise-driven approach: 648/1458 as against 800/1458.

Does this last result depend crucially on the fact that the random individual's chance of being right about the conjunction for the right reasons is less than a half, i.e. 4/9? We do not think so. If we do the corresponding calculations where the individual's chance of being right about either proposition is taken to be, say, 8/9 - and so with his or her chance of being right about the conjunction for the right reasons being 64/81 and greater than evens - we still find that the group's chance of being right for the right reasons is higher under the premise-driven approach. It is $495,616 / 531,441$ as against $471,040 / 531,441$.

\section{Conclusion}

These calculations give us solid if not absolutely certain grounds for the claims made in the text. These are, first, that the premise-driven procedure looks likely to do considerably better than the conclusion-driven in securing the chance of a majority being right for the right reasons about a conjunction; and second, that the conclusion-driven procedure appears to do better than the premisedriven one, though not by the same sort of margin, in securing the chance of a majority being right for no matter what reasons, right or wrong, about a conjunction. This conclusion applies to disjunctions as well. Any disjunction 'p or $q^{\prime}$ can be expressed as a negated conjunction: not(not $p$ and notq); and being right about a conjunction is equivalent, under our assumptions, to being right about its negation. 
${ }^{1}$ This means that there would be nothing to be gained by having electoral democracy impose the discipline of reason at the collective level. But it does not mean that we should abandon the ambition, common to most deliberative democrats, to make electoral democracy and politics as deliberative as possible. There may be reasons of a non-republican kind for seeking a deliberative dispensation, as we shall see in the fourth section. But in any event the republican rationale introduced in the third section itself suggests an argument in support of electoral discussion and deliberation. This is that such debate is likely to be important for a political democracy in helping it to establish a currency of considerations that can be invoked to support or challenge decisions of government. It can serve as a filter such that those considerations that go unchallenged in the electoral forum have a good claim to express common perceived concerns.

${ }^{2}$ Kornhauser and Sager (1993) suggest that while the straightforward premisedriven procedure is generally more satisfactory - more satisfactory from the point of view, roughly, of contestability - the court should resort to a higherlevel procedure in any case, like the one illustrated, where there is any doubt about this. It should take a majority meta-vote on which procedure to employ at the lower level, undertaking 'to justify its decision' (31; cf 33-36): that is, undertaking to find agreed premises such that the meta-vote can be represented as itself driven by majority endorsement of those considerations in a premisedriven way. Thus the higher-level considerations might be, first, that going along with the lower-level premise-driven decision in this instance would generate a certain result and, second, that the court ought to avoid such a result. Such considerations, if endorsed by a majority, might provide a higher-level, premisedriven case for going along with a different result from that which was supported by a lower-level, premise-driven procedure.

${ }^{3} \mathrm{I}$ am indebted to Geoff Brennan, who first made me aware of the dilemma. I was helped by comments received when versions were presented at Lund University, Nov 99; at a conference on 'Deliberating about Deliberative Democracy', University of Texas, Austin, Feb 00; at the annual Analytic Legal Philosophers' Conferece in New York, April 00; and at seminar presentations in Johns Hopkins University, New 
York University and Princeton University. I owe a particular debt to Wlodek Rabinowitz for his helpful comments and I was also greatly aided by discussions with a number of other people: David Estlund, Christian List, Victoria McGeer and Fred Schick. Bruce Chapman and Lewis Kornhauser sent me useful written comments on the paper. 